\title{
Crack propagation studies and bond coat properties in thermal barrier coatings under bending
}

\author{
A K RAY*, N ROY and K M GODIWALLA \\ National Metallurgical Laboratory, Jamshedpur 831 007, India
}

\begin{abstract}
Ceramic based thermal barrier coatings (TBC) are currently considered as a candidate material for advanced stationary gas turbine components. Crack propagation studies under bending are described that were performed on plasma sprayed $\mathrm{ZrO}_{2}$, bonded by MCrAlY layer to $\mathrm{Ni}$ base superalloy. The crack propagation behaviour of the coatings at room temperature in as received and oxidized conditions revealed a linear growth of the cracks on the coating till the yield point of the super alloy was reached. High threshold load at the interface between the ceramic layer and the bond coat was required to propagate the crack further into the bond coat. Once the threshold load was surpassed the crack propagated into the brittle bond coat without an appreciable increase in the load. At temperatures of $800^{\circ} \mathrm{C}$ the crack propagated only in the TBC (ceramic layer), as the ductile bond coat offered an attractive sink for the stress relaxation. Effects of bond coat oxidation on crack propagation in the interface region have been examined and are discussed.
\end{abstract}

Keywords. Coating; thermal barrier; bond coat; superalloy; crack propagation; zirconia; plasma spraying; stress; strain; modulus.

\section{Introduction}

Research on evaluating the lifetime of candidate superalloy turbine blade materials with ceramic coated thermal barrier coatings (TBC) under thermomechanical conditions has gained increasing interest in recent years. Plasma sprayed yttria (6-8\%) stabilized zirconia (PSZ) is currently the most advanced system envisaged for TBC applications on superalloy turbo engine components. Although this system is known for its excellent thermomechanical resistance at elevated temperatures, the relationship between performance and microstructure of such complex coatings is not fully understood (Lelait et al 1989). Yet TBCs represent an attractive material to enhance the high temperature limits of the superalloy engine components notwithstanding its limitations to spalling by oxidation of the bond coat (Miller and Lowell 1982; Liebert and Miller 1984; Miller and Berndt 1984; DeMasi et al 1989; Brindley and Miller 1990; Kokini et al 1997). NiCrAlY or NiCoCrAlY type metallic undercoat generally ensures the adherence of the bonding and the thermal barriers on the substrate and also improves the corrosion resistance of the coatings. At high temperatures, the interdiffusion processes (Duret 1986) between the bond coat and the substrate could be very important and in extreme cases, lead to a rapid degradation of the coating properties, like the Co base coating and rapid diffusion of $\mathrm{Al}$ from Co base coatings on Ni base superalloy at high temperatures with the formation of an intermediate

\footnotetext{
*Author for correspondence
}

brittle intermetallic layer. The coating could play its protective role only when it could withstand erosion and impact in addition to the induced thermomechanical stresses during on and off periods of the engine. In studying the life of TBCs in recent times more efforts have been made in studying the mechanisms of crack initiation and propagation under controlled experimental conditions (Lelait et al 1989; Kokini and Takeuchi 1994; Kokini et al 1997).

Keeping this in view, an attempt was made to study the crack propagation behaviour in TBCs at room temperature in as received and oxidized conditions at temperatures around $800^{\circ} \mathrm{C}$. The failure mode of the TBC system was studied in bending with in situ observation of the cracking mechanisms.

\section{Experimental}

\subsection{Materials}

Ni-base (inconel-617) alloy was taken as the substrate material on which NiCrAlY type metallic undercoat or bond coat was first applied by plasma spraying. Zirconia stabilized with $8 \mathrm{wt} \%$ yttria thermal barrier coating was applied over the bond coat by plasma spraying under reduced pressure and in an inert gas atmosphere (Brindley 1997). The substrate surface was initially treated by arc sputtering to remove any trace of oxide that might have formed during preheat. A gun-substrate distance of $~ 40$ $70 \mathrm{~mm}$ in a chamber with $4-8 \times 10^{-3} \mathrm{MPa}$ pressure was adopted for the coating. The feed rate was $4 \mathrm{~kg} / \mathrm{h}$ having a 
Table 1. Dimension and coating thickness of the TBC specimens for FPB experiments.

\begin{tabular}{lccccc}
\hline Type & $\begin{array}{c}\text { Test temperature } \\
\left({ }^{\circ} \mathrm{C}\right)\end{array}$ & $\begin{array}{c}h \\
(\mathrm{~mm})\end{array}$ & $\begin{array}{c}b \\
(\mathrm{~mm})\end{array}$ & $\begin{array}{c}d_{\mathrm{c}} \\
(\mathrm{mm})\end{array}$ & $\begin{array}{c}d_{\mathrm{b}} \\
(\mathrm{mm})\end{array}$ \\
\hline 1. As received & $R T-25$ & $1 \cdot 83$ & $2 \cdot 61$ & $0 \cdot 50$ & $0 \cdot 10$ \\
2. Oxidized at $1000^{\circ} \mathrm{C}$ for $200 \mathrm{~h}$ & $R T-25$ & $2 \cdot 41$ & $2 \cdot 22$ & $0 \cdot 30$ & $0 \cdot 10$ \\
3. As received & 800 & $3 \cdot 00$ & 3.88 & $0 \cdot 50$ & $0 \cdot 20$ \\
\hline
\end{tabular}

$h=$ height $b=$ width $d_{\mathrm{c}}=$ thickness of ceramic layer; $d_{\mathrm{b}}=$ thickness of bond coat.

gun operating power at $80 \mathrm{~kW}$. Specimens were prepared from these for the study.

\subsection{Specimen preparation}

The specimen for four-point bend tests (FPB) were cut and machined to the size shown in table 1 , where $h$ is the height, $b$ the width and $d_{\mathrm{c}}$ the thickness of the bond coat $\left(d_{\mathrm{b}}\right)$. Figure 1 shows the schematic cross sectional view of the multi layer specimen containing the substrate (type 1), bond coat interface (type 2), and the TBC (type 3 ) when oxidized.

\subsection{Microstructure}

The samples were polished for microstructural examination. The thickness of the TBC (ceramic layer) as well as that of the bond coat were measured by optical microscopy. Another set of samples were oxidized at $1000^{\circ} \mathrm{C}$ for $200 \mathrm{~h}$ in argon having $20 \mathrm{vol} \%$ oxygen atmosphere at $10^{5} \mathrm{~Pa}$. Samples were electrochemically etched with an electrolyte having $35 \mathrm{ml} \mathrm{H}_{2} \mathrm{SO}_{4}, 40 \mathrm{ml} \mathrm{H}_{3} \mathrm{PO}_{4}$ and $25 \mathrm{ml}$ $\mathrm{H}_{2} \mathrm{O}$. Typical micrographs of as received and oxidized conditions are shown in figure $2 \mathrm{a}$ and $\mathrm{b}$ respectively.

\subsection{Crack propagation studies}

Crack propagation studies were made under the four-point bend (FPB) loading using a miniature testing device monitored on the stage of an optical microscope and an servohydraulic actuated Instron -1362 machine for $800^{\circ} \mathrm{C}$ tests. The TBC (ceramic layer) was on the tensile surface. The ramp rate for loading was maintained as $2.5 \mathrm{~N} \mathrm{~s}^{-1}$ and the deflection was measured with an LVDT. The load vs deflection curves were recorded as the raw data from each experiment. Most tests were conducted at room temperature where the bond coat was brittle but those tested at $800^{\circ} \mathrm{C}$ were ductile. Strain values corresponding to deflection were evaluated on the basis of geometric two layer relations (Chiu and Case 1991) using

$$
\begin{aligned}
& \varepsilon=h_{0} / R, \\
& R=\delta /[1-\cos (\theta / 2)]=\delta /\left[1-\cos \left\{\sin ^{-1}(\delta / L / 2)\right\}\right],
\end{aligned}
$$

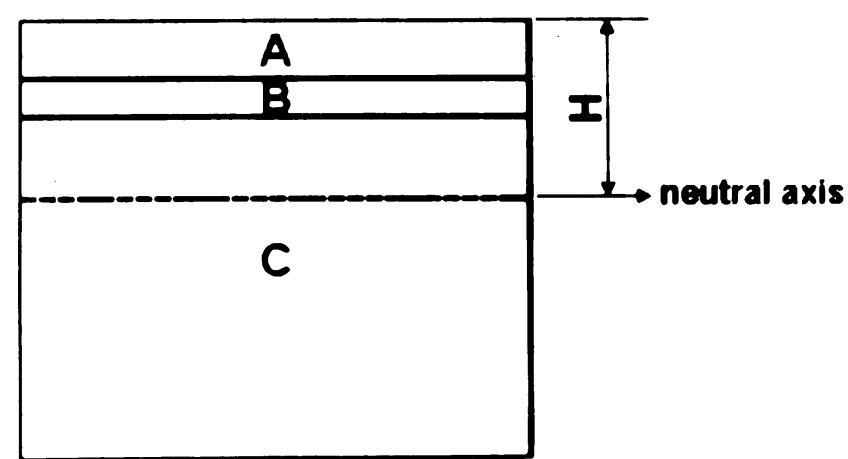

Figure 1. Schematic of cross-sectional view of a plasma sprayed TBC on Ni base superalloy (A, TBC (ceramic layer); $\mathrm{B}$, bond coat, $\mathrm{C}$, substrate (Ni base superalloy) and $\mathrm{H}$, distance of neutral axis from the surface of the TBC).

where $\varepsilon$ is the strain corresponding to deflection $\delta, L$ the difference between the outer and inner span in four-point bend loading, $h_{0}$ the distance of the neutral axis of the FPB specimens from the interface of the ceramic coating and the bond coat. $R$ is the radius of curvature of the neutral axis due to the deflection at an angle $\theta$ and $h_{0}$ is calculated from

$$
h_{0}=E_{\mathrm{s}} d_{\mathrm{s}}^{2}-E_{\mathrm{c}} d_{\mathrm{c}}^{2} / 2\left(E_{\mathrm{s}} d_{\mathrm{s}}+E_{\mathrm{c}} d_{\mathrm{c}}\right)
$$

where $E_{\mathrm{s}}=210 \mathrm{GPa}$ and $E_{\mathrm{c}}=110$ and $108 \mathrm{GPa}$ at $800^{\circ} \mathrm{C}$ (Ray et al 1996; Ray and Steinbrech 1998). $E_{\mathrm{s}}, E_{\mathrm{c}}$ and $d_{\mathrm{s}}$, $d_{\mathrm{c}}$ are the elastic moduli and thickness of the substrate and ceramic layer of TBC respectively. Typical load vs deflection and derived stress vs strain curves of the composite beam specimen are shown in figures $3 a$ and $b$ respectively. Whilst the variation of crack length with load and deflection are shown in figures $4 \mathrm{a}-\mathrm{c}$.

The TBC inherited many microcracks due to plasma spraying, but under the bending stresses bigger cracks became prominent and grew across the thickness of the specimen. The crack lengths were monitored microscopically on the side surface of the specimens. The crack path trajectory was recorded and printed by a video camera with a special attachment for $800^{\circ} \mathrm{C}$ tests. Crack deflection occurred as the propagating cracks met with a resistance. The deflection with crack length was plotted and shown in figures $5 \mathrm{a}$ and $\mathrm{b}$. Subsequently, these deflection 

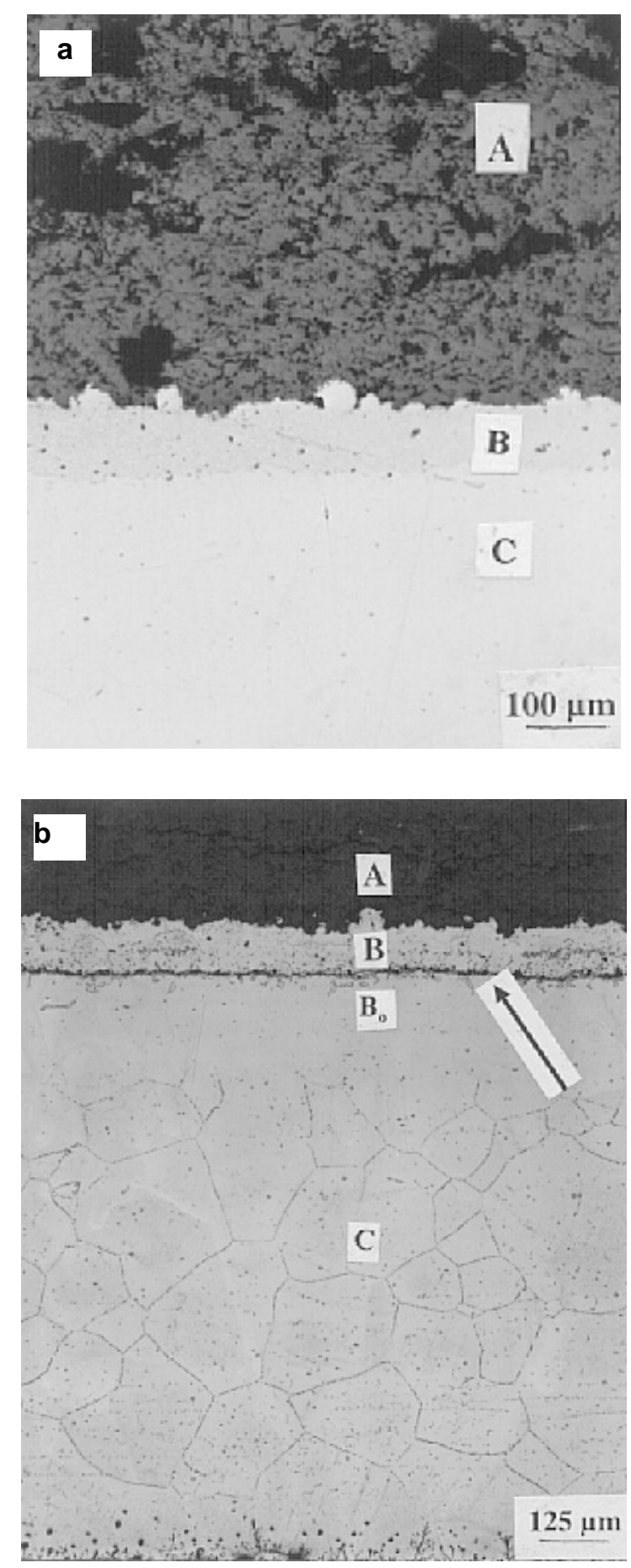

Figure 2. a. Micrograph of a plasma sprayed $\mathrm{TBC}$ in as received condition (type 1). The sample is polished and unetched. The TBC (ceramic layer) possesses pores as processing defects incorporated by the plasma spraying process. The bond coat is also found to possess a lot of porosity as processing defect (A, TBC (ceramic layer); B, bond coat and C, substrate) and $\mathbf{b}$. micrograph of oxidized specimen (type 2 ) at a low magnification. Al depleted zone is seen after the bond coat. Arrow indicates carbide precipitation which is seen at the interface of bond coat and substrate. Note also the carbide precipitation within the coarsened grains in the substrate. (A, TBC (ceramic layer); $\mathrm{B}$, bond coat, $\mathrm{B}_{0}, \mathrm{Al}$ depleted zone and $\mathrm{C}$, substrate). values were plotted against their corresponding load values by a best fit polynomial of the form,

$$
Y=A+B x+C x^{2}+D x^{3}
$$

and by resorting to the integral method. The value of the energy, $U=\int Y \mathrm{~d} x$ were evaluated corresponding to each deflection values enabling raw data plots of $U$ vs $c$ (crack length). The slope of the various points corresponding to the crack lengths when normalized with respect to the height of the specimen gave the strain energy release with respect to crack extension during bending. The strain energy released at the interface of the ceramic coating and the bond coat and within the bond coat are shown in table 2. From the load deflection curves of the bent composite beam the bending stresses were evaluated without TBC (ceramic layer) using the standard formula as per ASTM STP 410 for the four-point bend loading of the miniature specimen.
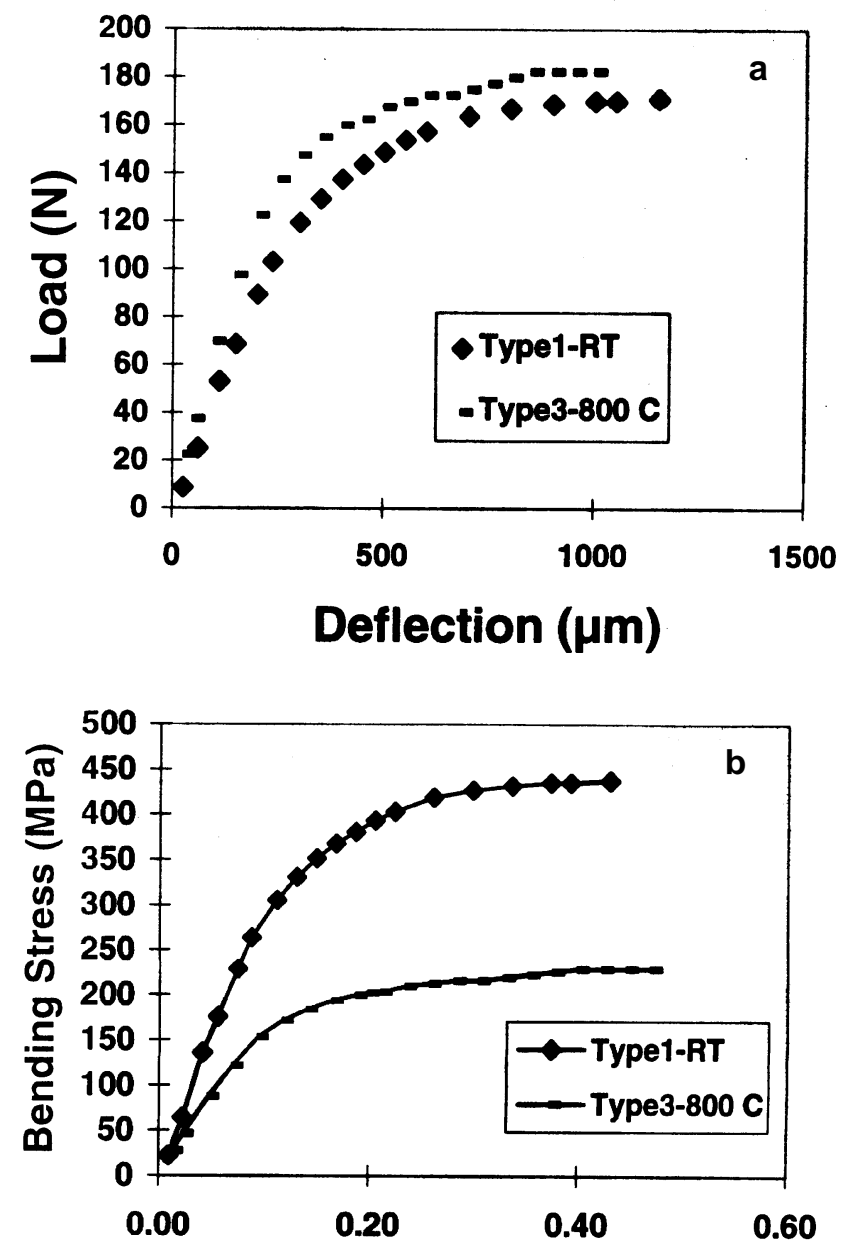

\section{Strain at the Ceramic (TBC) Surface (\%)}

Figure 3. a. Load vs deflection curves for composite beam specimens (types 1 and 3) and b. stress vs strain curves for composite beam specimens (types 1 and 3 ). 


\section{Results and discussion}

\subsection{Metallographic studies}

Micrographs of the plasma sprayed TBC substrate (type 1) revealed the presence of porous defects arising out of the processing. It was also evident that the bond coat also possessed a large quantity of porosities. Carbides precipitation at the grain boundaries and within the grains were also seen. An Al depleted zone just below the TBC along the TBC/bond coat interface as well as at the bond coat/substrate interface was also observed (figure $2 b$ ). Similar observation was also recorded by Brandle et al (1996) on the oxidation behaviour of sprayed MCrAlY coatings in air and in $1 \% \mathrm{O}_{2}, 1050{ }^{\circ} \mathrm{C}$ atmosphere. The $\mathrm{Al}$
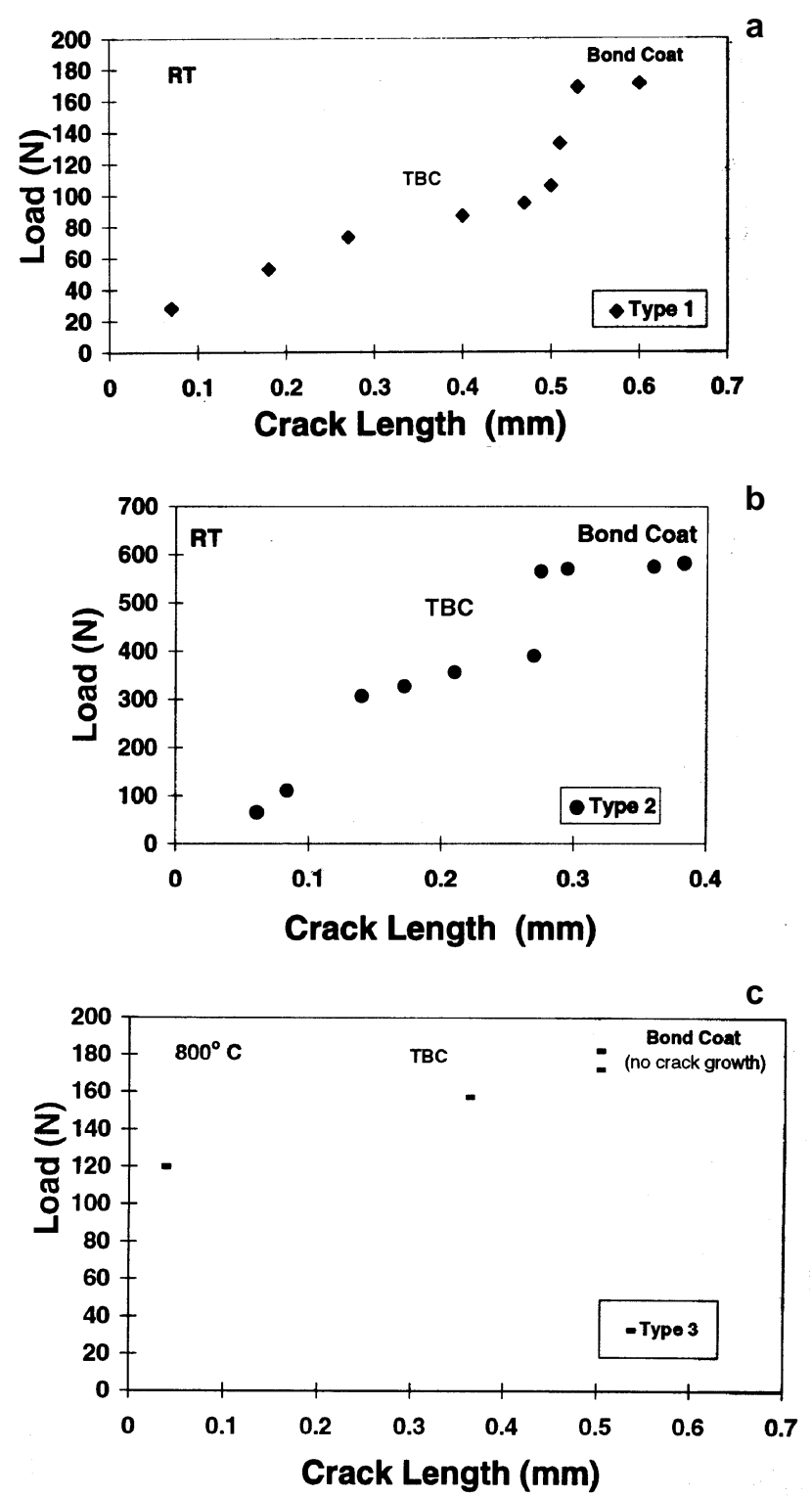

Figure 4. Plot of load vs crack length for the composite beam specimens a. type 1 , b. type 2 and c. type 3 . depletion was primarily due to its oxidation to $\mathrm{Al}_{2} \mathrm{O}_{3}$ and Al diffusing into the substrate.

\subsection{Mechanical properties and crack propagation behaviour of the TBCs}

In contrast to a homogeneous rectangular beam subjected to symmetrical bending, the neutral axis of an inhomogeneous beam (the composite case under study) gets shifted from the centroid of the cross-section of the composite beam. Thus an in-plain modulus of the coating was proposed from the shift of the neutral axis (Timoshenko and Young 1962). The elastic moduli of the three-layered composite beam was calculated by modifying and generalizing the method adopted by Chiu and Case (1991). The distance of the neutral axis from the bond-substrate interface, $H^{\prime}$, was derived as,

$$
H^{\prime}=d_{\mathrm{s}}-(K / K+1)\left(d_{\mathrm{b}}+d_{\mathrm{c}}+d_{\mathrm{s}}\right),
$$

where $K$ is $-\varepsilon_{\mathrm{s}} / \varepsilon_{\mathrm{c}}$. The strain in substrate $\varepsilon_{\mathrm{s}}=Y / R$, where $Y$ is the transverse coordinate from the neutral axis and $R$ being the radius of the neutral axis. The normal stresses $\sigma_{\mathrm{c}, \mathrm{s}, \mathrm{b}}$ of the bent composite beam are described (Timoshenko and Young 1962) as $\sigma_{\mathrm{c}, \mathrm{s}, \mathrm{b}}=E_{\mathrm{c}, \mathrm{s}, \mathrm{b}} Y / R$, where the subscripts $\mathrm{c}, \mathrm{s}, \mathrm{b}$ are for the ceramic, substrate and bond coat respectively.
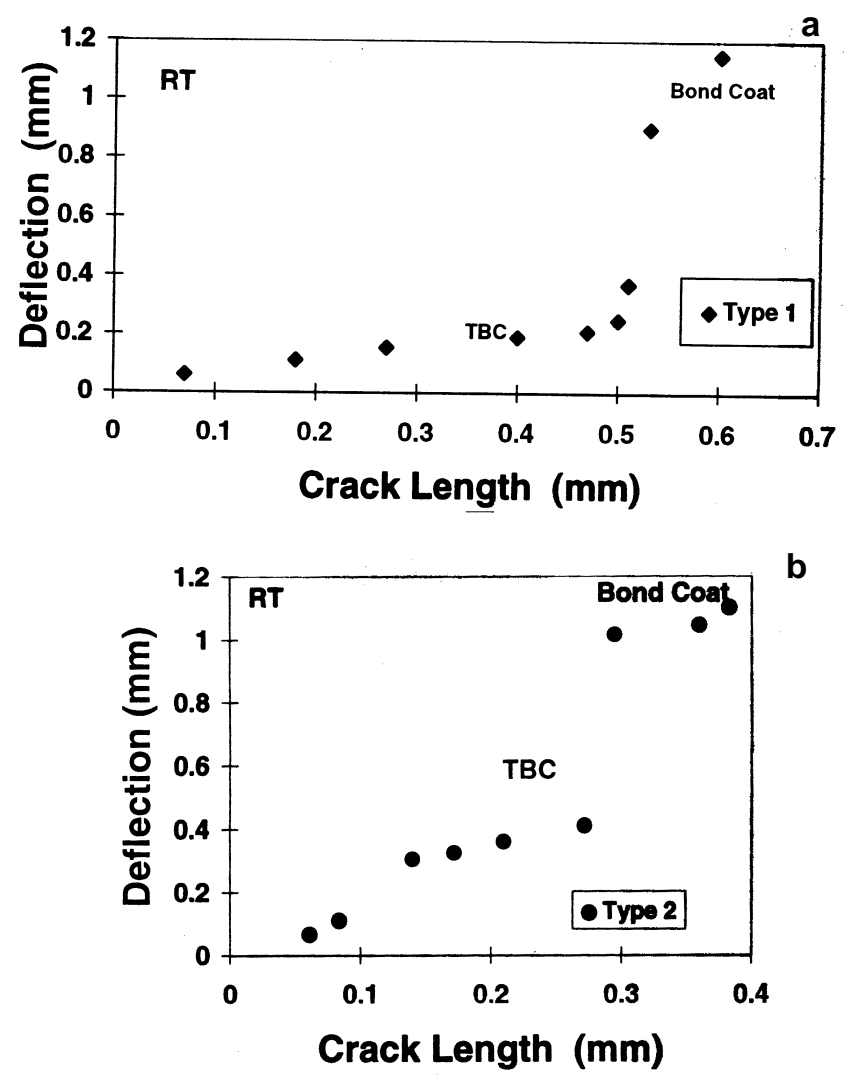

Figure 5. Plot of deflection vs crack length for the composite beam specimens a. type 1 and $\mathbf{b}$. type 2 . 
The value of moduli at $R T$, oxidized and $800^{\circ} \mathrm{C}$ were determined from the slopes of the elastic region of the experimentally determined $\sigma-\varepsilon$ curves. In these curves the $\%$ strains at the bond coat/TBC interface were plotted against the corresponding bending stresses for the composite of the specimens. Taking into account the relative mechanical properties of the superalloy and the coating, the latter has a low strength and modulus due to numerous defects incorporated during processing. The system thus could be considered as a composite in which the load bearing contribution of the coating is negligible (Duret et al 1986). Thus in the present investigation it was assumed that the load is borne by the superalloy and not by the coating. The bending stresses at the yield point were $296 \mathrm{MPa}, 693 \mathrm{MPa}$, and $200 \mathrm{MPa}$ for the substrate (type 1), interface (type 2), and oxidized (type 3) respectively. The high interface values could be due to the strengthening by the carbide diffusion and precipitation. The experimental values of $E_{\mathrm{b}}$ and $\varepsilon_{\mathrm{s}}$ are shown in table 3 . The value of $210 \mathrm{GPa}$ compares well with the estimated value of $209 \cdot 17 \mathrm{GPa}$.

Table 2 indicates that the oxidized sample required higher strain energy for the crack to penetrate the bond coat compared to the as received TBC. For the growth of the stable cracks study in a brittle material like ceramic notched and precracked samples are usually desired. In the present investigation precracking was ignored due to the presence of porosity and defect structure that would induce crack growth under the applied bend stress. Figures 6-8 show the morphology of the crack extended

Table 2. Strain energy values at the interface of bond coat and TBC and in the bond coat of the FPB composite specimens.

\begin{tabular}{lcccc}
\hline & & \multicolumn{2}{c}{ Strain energy released $\left(\mathrm{J} / \mathrm{cm}^{2}\right)$} & \\
\cline { 3 - 4 } Type & $\begin{array}{c}\text { Test temperature } \\
\left({ }^{\circ} \mathrm{C}\right)\end{array}$ & At the interface & Within the bond coat & $\begin{array}{c}\text { Strain at the interface } \\
\text { of bond coat/TBC }\end{array}$ \\
\hline 1. As received & $R T-25$ & 131 & $23 \cdot 7$ & $\sim 0 \cdot 10$ \\
2. Oxidized at $1000^{\circ} \mathrm{C}$ for $200 \mathrm{~h}$ & $R T-25$ & 170 & $17 \cdot 6$ & $\sim 0 \cdot 20$ \\
3. As received & 800 & 5.4 & - & $0 \cdot 34$ \\
\hline
\end{tabular}

Table 3. Values of $\varepsilon_{\mathrm{s}}$ and $E_{\mathrm{s}}$ determined from the experimental data.

\begin{tabular}{lccc}
\hline Type & $\begin{array}{c}\text { Test temperature } \\
\left({ }^{\circ} \mathrm{C}\right)\end{array}$ & $\begin{array}{c}\% \text { strain in substrate } \\
\left(\varepsilon_{\mathrm{s}}\right)\end{array}$ & $\begin{array}{c}\text { Young's modulus } \\
\text { substrate }\left(E_{\mathrm{s}}\right) \mathrm{GPa}\end{array}$ \\
\hline 1. As received & $R T-25$ & 0.0282 & 210 \\
2. Oxidized at $1000^{\circ} \mathrm{C}$ for $200 \mathrm{~h}$ & $R T-25$ & 0.0652 & 204 \\
3. As received & 800 & 0.0300 & 200 \\
\hline
\end{tabular}

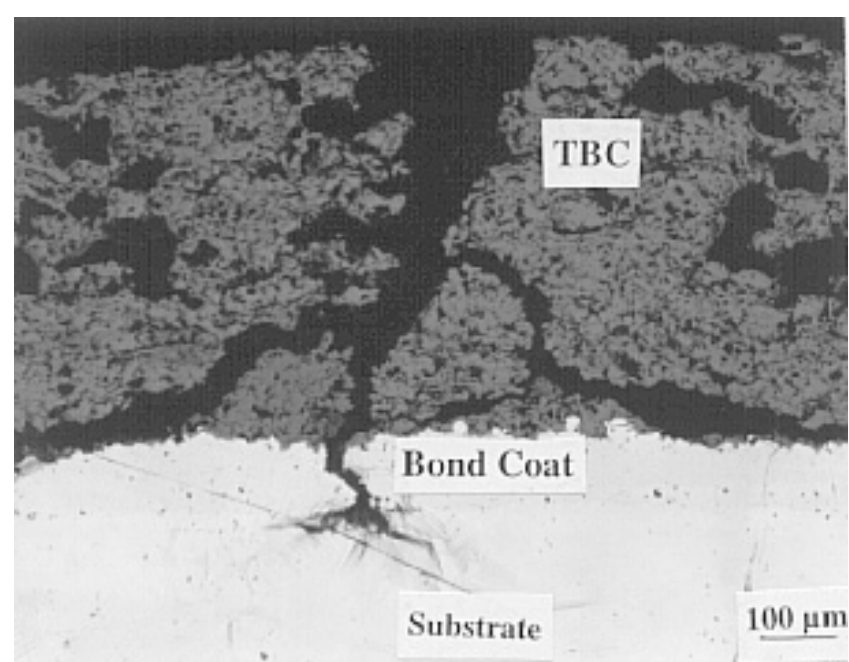

Figure 6. Crack path trajectory in the TBC (ceramic layer) and in the bond coat in crack propagation studies under bending at $R T$ of type 1 composite beam specimen. Crack branching in the TBC, crack tip blunting at the interface of bond coat/ substrate and severe crack deflection in the bond coat is seen.

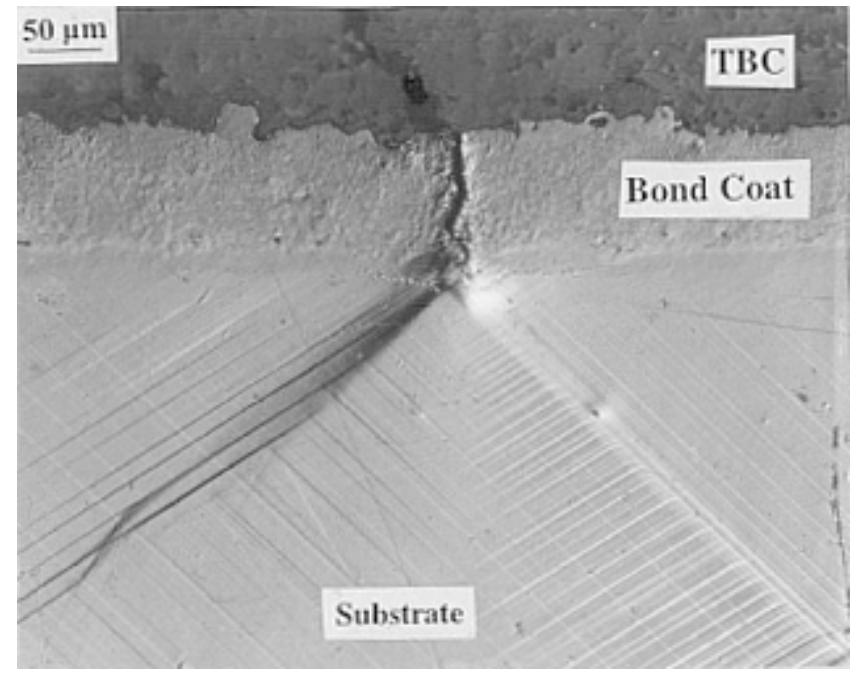

Figure 7. Crack path trajectory in the bond coat in crack propagation studies at $R T$ of type 2 composite beam specimen in heat treated condition (oxidized at $1000^{\circ} \mathrm{C}$ for $200 \mathrm{~h}$ ). The crack front penetrates vertically into the bond coat from the TBC (top most layer). The substrate reveals substantial deformation twins. 
paths as recorded from the video scanner. It is evident from figures $4 \mathrm{a}$ and $\mathrm{b}$ that the cracks propagated linearly in the TBC with increase in the bending loads till the yield point of the substrate was reached. Thereafter at the interface of the TBC and bond coat a high threshold load was required for the crack to propagate further in the bond coat. Once the threshold was reached the crack propagated faster in the bond coat without any appreciable increase in the load with almost a zero slope. Deflection vs crack length curves shown in figures $5 \mathrm{a}$ and $\mathrm{b}$

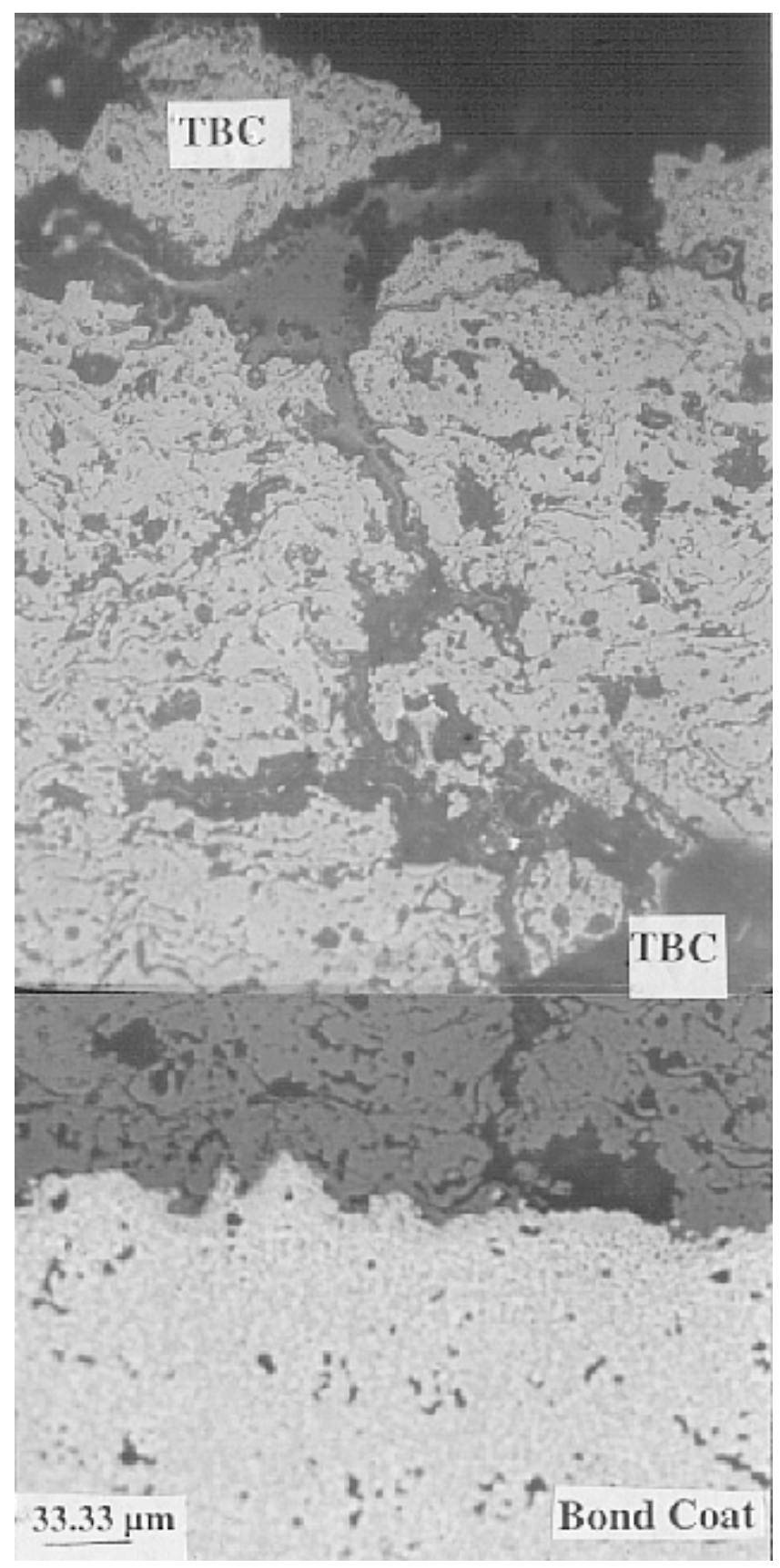

Figure 8. Typical crack path trajectory in the $\mathrm{TBC}$ at $800^{\circ} \mathrm{C}$ in type 3 composite beam specimen. Crack growth at $800^{\circ} \mathrm{C}$ was confined only to the TBC (ceramic layer). revealed positive linear dependence of the crack length with deflection in the ceramic layer as well as in the bond coat. The large amount of deformation slip bands in the metal substrate was indicative of plastic deformation ahead of the crack front at the bond/substrate interface with crack blunting when tested in $R T$. There was no evidence of spalling of the TBC in any of the bend tests performed in $R T$ and at $H T$.

It is noteworthy that the crack path trajectory in the TBC (ceramic layer) often showed crack branching and deflection, shown in figures 6 and 8 respectively. At temperatures of $800^{\circ} \mathrm{C}$ the crack was found to propagate only in the TBC as the coating having ductility at these temperatures offered an attractive means of protecting the substrate material from thermal loads. This is indicative of the high strain of $0.34 \%$ at the interface of the bond coat/TBC at $800^{\circ} \mathrm{C}$ compared to $R T$ bend tests of the composite beam specimens (table 2 and figure $3 \mathrm{~b}$ ). Much of the failures of such coatings has been attributed to the thermal expansion mismatch between the ceramic coat and the ductile substrate primarily arising during cooling cycle. The crack in the TBC during cooling was monitored in the present study but showed no increase in length. This could be due to the compressive stresses in the ceramic layer placed by the larger expansion of the metallic substrate. Previous authors (Takeuchi et al 1992; Pierz 1993) also expressed similar assumptions in their finite element analyses of their samples tested under actual operating environments.

\section{Conclusions}

The significant effects of oxidation on the deformation behaviour of TBCs in the present investigation have been outlined and discussed. In crack propagation studies it was clear that for the oxidized samples in the TBC (ceramic layer), crack growth was observed even at constant load as is evident from the change in the slope of the load vs crack length curve. The porosities played a definitive role in acting as stress raisers and initiating cracks. Higher temperature heat treatments at $1000^{\circ} \mathrm{C}$ for $200 \mathrm{~h}$ densified the $\mathrm{TBC} /$ ceramic coating thereby reducing the probability of crack source, yet permitting the cracks to propagate unhindered by the reduced pores acting as sinks. Consequently, crack growth was noticed within the TBC at constant load in the case of oxidized specimens. At $800^{\circ} \mathrm{C}$, the crack front propagated only in the $\mathrm{TBC}$ and not in the bond coat due to its increased ductility at these temperatures offering an attractive sink for stress relaxation. However, as the crack front approached the interface of the bond coat and the ceramic layer a higher threshold stress was required for the crack to propagate into the bond coat of the oxidized layer. Deflection vs crack curves revealed a positive linear dependence of the crack length with deflection in the ceramic layer of the TBC as well as the bond coat. 


\section{Acknowledgements}

The data presented in this paper is the outcome of a part of the project on 'Thermomechanical characterization and modelling of ceramic coatings in power plant application' carried out at IWE-1, Forschungszentrum, Julich, Germany. This part of the programme was an Indo-German collaboration under the bilateral exchange scheme. One of the authors (AKR) is grateful to DLR, Bonn, for financial support during the research stay at IWE-1, Julich, Germany.

Sincere thanks are due to Ms G Blandin, S Brunnings, J Monch, Dr D Dasu, Central Glass and Ceramic Research Institute, Kolkata, for their assistance in the high temperature testing and to Mr Schiffers, Ms Marlise Felden, Mr Gutzit and all fellow colleagues of IWE-1, Julich for their constant help.

\section{References}

Brandle W, Grabke H J, Toma D and Krueger J 1996 Surf. Coat. Technol. 86-87 39

Brindley W J and Miller R A 1990 Surf. Coat. Technol. 43-44 446
Brindley W J 1997 J. Thermal Spray Tech. 685

Chiu C C and Case E D 1991 Mater. Sci. Eng. A132 39

DeMasi J T, Sheffler K D and Ortiz M 1989 NASA CR 1822 30

Duret C 1986 COST Energy EUR 10682 EN (ed.) O Morocutti (Belgium: Commission of the European Communities)

Kokini K, Choules C D and Takeuchi Y R 1997 J. Therm. Spray Tech. ASM Int. 643

Kokini K and Takeuchi Y R 1994 Mater. Sci. Eng. A189 301

Lelait K, Alperine S, Diot C and Marvel M 1989 Mater. Sci. Engg. A120-121 475

Liebert C H and Miller R A 1984 Ind. Eng. Chem. Prod. Res. Dev. 12334

Miller R A and Lowell C E 1982 Thin Solid Films 95265

Miller R A and Berndt C C 1984 Thin Solid Films 119195

Pierz P M 1993 Surf. Coat. Technol. 6160

Ray A K, Fuller E R and Banerjee S 1996 J. Eur. Ceram. Soc. 16503

Ray A K and Steinbrech R W 1998 Int. Rept. of Indo-German Proj. No-IN-233

Takeuchi Y R, Kokini K and Yonushonis T M 1992 Proc. coatings for adv. heat engines workshop (US Dept. of Energy) p. II-30

Timoshenko S P and Young D H 1962 Strength of mater. (Princeton, NJ: Van Nostrand Reinhold) 4th edn. p. 113 